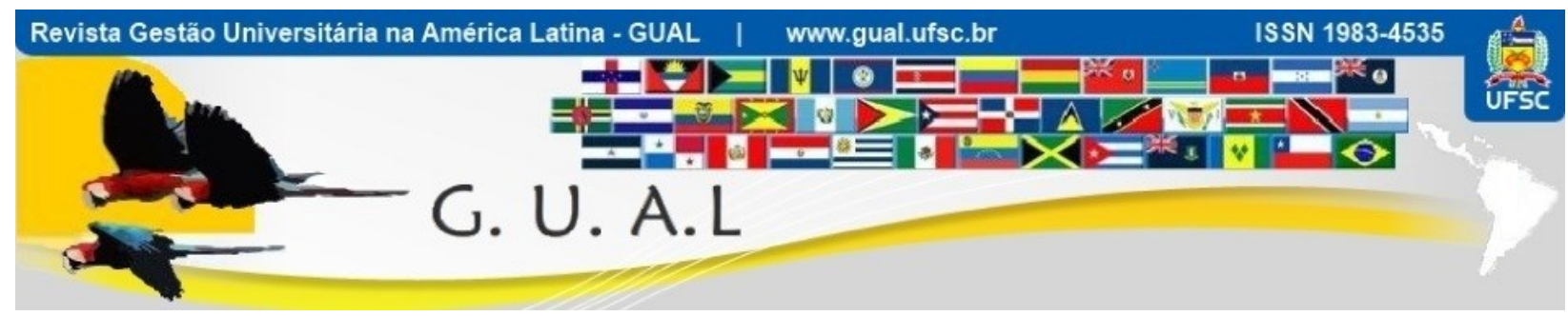

DOI: http://dx.doi.org/10.5007/1983-4535.2018v11n2p47

\title{
AS INTERAÇÕES ENTRE OS ATORES DA PÓS- GRADUAÇÃO STRICTO SENSU EM ADMINISTRAÇÃO: UMA ANÁLISE DO INDIVÍDUO E DA COLETIVIDADE
}

INTERACTIONS AMONG POST GRADUATION ACTORS (STRICTO SENSU) IN MANAGEMENT: AN ANALYSIS OF THE INDIVIDUAL AND THE COLLECTIVITY

Eduardo Guedes Villar, Doutorando Universidade Federal do Paraná - UFPR eduardogvillar@gmail.com

Recebido em 23/setembro/2016

Aprovado em 26/fevereiro/2018

Sistema de Avaliação: Double Blind Review

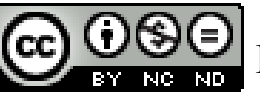

Esta obra está sob uma Licença Creative Commons Atribuição-Uso. 


\title{
RESUMO
}

Neste artigo objetivou-se compreender como se relacionam os professores dos programas de stricto sensu em Administração entre si e com os outros atores deste nível de ensino. Realizou-se um estudo de caso múltiplo por meio de entrevistas com os professores e análise documental dos currículos lattes. Verificou-se que os problemas de comunicação, a falta de articulação, a restrição de tempo, a concentração do conhecimento e a independência do pesquisador dificultam a interação entre os professores de um mesmo programa. Evidenciouse, ainda, que as atividades de interação existentes entre os professores raramente contemplam questões de ensino. Identificou-se, ainda, os órgãos como o CNPq, as Fundações Estaduais de Fomento a Pesquisa e a CAPES como entidades que participam do campo em análise. Destacam-se ainda os padrões de conduta estimulados pelo sistema de avaliação da CAPES, por meio do estabelecimento da métrica de pontos para a publicação.

Palavras-chave: Stricto sensu. Atores sociais. Ensino. Pesquisa.

\begin{abstract}
In this paper we aimed to understand how professors of Management Post Graduate programs relate among themselves and with other stakeholders of higher education. We conducted a multiple case study through interviews with professors and document analysis of lattes curricula. It was found that communication problems, lack of coordination, the time constraint, the concentration of knowledge and the independence of the researcher hinder the interaction among professors of the same program. It was evident also that the activities of existing interaction among professors rarely address issues of education. It was also identified institutions such as CNPq, the State Foundations of Research Development and CAPES as entities that participate in field analysis. We also highlight the standards of conduct encouraged by the CAPES evaluation system, through the establishment of metrics points to the publication.
\end{abstract}

Keywords: Post Graduate Programs. Social actors. Teaching and Research. 


\section{AS INTERAÇÕES ENTRE OS ATORES DA PÓS-GRADUAÇÃO STRICTO SENSU EM \\ ADMINISTRAÇÃO: UMA ANÁLISE DO INDIVÍDUO E DA COLETIVIDADE \\ DOI: http://dx.doi.org/10.5007/1983-4535.2018v11n2p47}

\section{INTRODUÇÃO}

A pós-graduação stricto sensu, abordada nesta subseção, foi iniciada no país na década de 1970 apenas com programas de mestrado (BERTERO, 2006). Segundo esse autor, em apenas duas instituições, a Universidade de São Paulo e a Fundação Getúlio Vargas, ambas em São Paulo, foram criados, ainda na década referida, programas de doutorado. A distinção entre stricto sensu e lato sensu, no retrospecto de Bertero (2006), remonta à década de 1960 e foi criada por meio de um parecer do Conselho Federal de Educação que se utilizou dessas expressões latinas para indicar que, após a graduação, poderiam ser trilhados dois caminhos distintos.

O Parecer 977, publicado pelo Conselho Federal de Educação, segundo Santos (2003), estabeleceu a pós-graduação conforme o modelo norte-americano. No parecer, a pósgraduação stricto sensu dar-se-ia em dois níveis independentes e sem relação de pré-requisito entre o primeiro e o segundo (mestrado e doutorado). Esses cursos compreendem a realização de um conjunto de disciplinas e culminam com a elaboração e defesa de um trabalho de conclusão de curso (dissertação ou tese) (PEZZI; STEIL, 2009).

Segundo Ikeda, Campomar e Veludo-de-Oliveira (2005), no Brasil, na categoria stricto sensu, podem ser enquadrados os cursos de mestrado acadêmico, mestrado profissional e doutorado. De acordo com esses autores, o mestrado acadêmico e o doutorado possuem uma ênfase acadêmica, diferente do mestrado profissional, o qual possui uma orientação mais voltada para o mercado. Ressalta-se que esses cursos se diferenciam dos cursos de especialização e MBAs, os quais se encaixam na categoria lato-sensu (IKEDA; CAMPOMAR; VELUDO-DE-OLIVEIRA, 2005).

O principal objetivo dos cursos de mestrado e doutorado, segundo Pezzi e Steil (2009), consiste na formação de pesquisadores em pesquisa científica e treinamento avançado. A expansão dos programas stricto sensu, sob a perspectiva de Bertero (2006), está relacionada à reforma da universidade e à necessidade de prover quadros de docentes e pesquisadores para o sistema. $\mathrm{O}$ autor indica que a legislação e os critérios de avaliação privilegiam as IES que possuem pessoas com mestrados e doutorados em seus quadros docentes. Dessa forma, mestrados e doutorados passaram a ser necessários, em grande número de IES, ao ingresso e avanço em carreiras acadêmicas (BERTERO, 2006).

A pós-graduação stricto sensu brasileira apresentou um crescimento expressivo nas últimas décadas. A grande área de Ciências Sociais Aplicadas contava com 111 cursos de 


\section{AS INTERAÇÕES ENTRE OS ATORES DA PÓS-GRADUAÇÃO STRICTO SENSU EM \\ ADMINISTRAÇÃO: UMA ANÁLISE DO INDIVÍDUO E DA COLETIVIDADE \\ DOI: http://dx.doi.org/10.5007/1983-4535.2018v11n2p47}

mestrado e doutorado em 1998, perfazendo um total de 8,8\% dos cursos stricto sensu no país. Em 2009, o número de cursos da área subiu para 344, o que corresponde a 12,7\% do total. As áreas de Administração, Ciências Contábeis e Turismo possuem 135 cursos stricto sensu. Desse total, os programas de Administração oferecem 55 mestrados, 27 doutorados e 27 mestrados profissionalizantes (CAPES, 2013).

Apesar deste crescimento, verificou-se uma carência de pesquisas que buscam, de maneira qualitativa, entender as particularidades que envolve pesquisar e ensinar neste nível de ensino. Para a realização desta pesquisa, busca-se entender o professor como ator social e suas relações com os outros atores da área. Segundo Berger e Luckmann (2012) a análise da interação de papéis sociais pode revela as mediações existentes entre os universos macroscópicos de significação, ou seja, significados institucionalizados coletivamente e objetivados por uma sociedade, bem como os modos pelos quais esses universos são subjetivamente reais para os indivíduos.

Portanto, objetiva-se nesta pesquisa compreender como se relacionam os professores dos programas de stricto sensu em Administração entre si e com os outros atores deste nível de ensino.

Neste sentido, uma análise de interação de papéis, no entendimento de Berger e Luckmann (2012), pode ser realizada de maneira conjunta (indivíduo e coletividade) somente se indagar sobre os modos pelos quais o indivíduo, em sua atividade social total, se relaciona com a coletividade em questão. Dessa forma, mesmo por meio da realização de entrevistas com indivíduos, um exame conjunto desses indivíduos e de suas relações pode trazer informações significativas sobre o comportamento da coletividade.

Por meio desta pesquisa, que busca verificar a interação entre os atores do stricto sensu, espera-se encontrar evidências mais apuradas sobre a estruturação dos programas stricto sensu em Administração. Por essa razão, acredita-se que os resultados deste estudo possam contribuir para o aprimoramento do ensino e da pesquisa neste nível de ensino, dando subsídios para o entendimento de condutas e comportamentos dos profissionais da área e dos atores com os quais se relacionam.

Ressalta-se, ainda, que esta pesquisa se encontra delimitada à pós-graduação stricto sensu em Administração, por se entender que esse nível de ensino é responsável pela formação dos futuros professores e pesquisadores no ensino superior (IKEDA; 


\section{AS INTERAÇÕES ENTRE OS ATORES DA PÓS-GRADUAÇÃO STRICTO SENSU EM ADMINISTRAÇÃO: UMA ANÁLISE DO INDIVÍDUO E DA COLETIVIDADE DOI: http://dx.doi.org/10.5007/1983-4535.2018v11n2p47}

CAMPOMAR; VELUDO-DE-OLIVEIRA, 2005), pela maior parte da produção científica brasileira e pelo seu crescimento tanto qualitativo quanto quantitativo (DANTAS, 2004).

Estruturou-se este artigo em 5 seções, das quais além desta introdução, apresentar-se-á uma segunda seção contendo um detalhamento de características e interações de atores dos programas stricto sensu em Administração no Brasil. Conta-se ainda com a terceira seção contendo informações sobre o delineamento metodológico desta pesquisa qualitativa e com a quarta seção com a apresentação dos dados da interação entre os atores e sua posterior interpretação. Por fim, apresenta-se a quinta e última seção com as considerações finais do trabalho, suas limitações e suas contribuições.

\section{FUNDAMENTAÇÃO TEÓRICA}

No Brasil, a regulamentação e a avaliação dos programas de pós-graduação stricto sensu em todas as áreas do conhecimento são de competência da CAPES. A avaliação dos programas é realizada por meio do Sistema Nacional de Avaliação da Pós-Graduação da CAPES, o qual possui como objetivos: a) o estabelecimento de padrões de qualidade para o mestrado e o doutorado e a identificação dos cursos que atendam a esse padrão; b) a contribuição para o aprimoramento de cada programa de pós-graduação por meio da realização de um parecer acerca dos pontos fortes e fracos do projeto do programa e de seu desempenho. Essa avaliação é realizada a cada três anos (em triênios) pelas comissões de áreas de conhecimento da CAPES, com acompanhamento anual, e abrange todos os programas e cursos que integram o Sistema Nacional de Pós-Graduação (SNPG) (CAPES, 2014).

Segundo Maccari (2008), as coordenações dos programas de pós-graduação em Administração no Brasil consideram o sistema de avaliação da CAPES como um norteador de suas ações e metas. $\mathrm{O}$ autor, em um estudo comparativo entre a avaliação realizada no strictosensu brasileiro e no norte-americano, indica que o sistema de avaliação da CAPES tem ajudado os programas a direcionarem seus esforços e investimentos, tanto em termos de infraestrutura quanto para a produção intelectual, culminando na melhoria de seu desempenho.

Contudo, essa avaliação, por ser de natureza preponderantemente quantitativa, induz à produtividade (ALCADIPANI, 2011). Segundo o autor, não se trata de um problema do órgão ou do sistema de avaliação. A maneira como os programas de stricto sensu encaram esse 


\section{AS INTERAÇÕES ENTRE OS ATORES DA PÓS-GRADUAÇÃO STRICTO SENSU EM ADMINISTRAÇÃO: UMA ANÁLISE DO INDIVÍDUO E DA COLETIVIDADE DOI: http://dx.doi.org/10.5007/1983-4535.2018v11n2p47}

sistema de avaliação da CAPES é que induz os pesquisadores ao produtivismo. Os programas, nesse sentido, passam a não valorizar o que não pode ser mensurado e, portanto, limitam o planejamento e a promoção de atividades fora dos indicadores do sistema (SANTOS, 2004).

O sistema de avaliação da CAPES, segundo Maccari (2008), por estabelecer os critérios mínimos de qualidade para os programas do stricto sensu, direciona os novos programas, ainda não solidificados, a uma rápida estruturação. Contudo, os programas já solidificados não são estimulados a ampliarem suas competências e inserção social, pois já cumprem os padrões mínimos.

No que tange à relação entre os programas de stricto sensu, Mello, Crubellate e Rossoni (2009) realizaram uma pesquisa por meio da qual estabeleceram um comparativo quanto à interação entre os pesquisadores desses programas nos triênios de 2001-2003 e 20042006. Os autores evidenciaram o aumento da cooperação entre os autores, com um crescimento significativo de coautorias nas publicações realizadas no último período em estudo. Em outro estudo, entretanto, Oliveira (2013) verificou que os pesquisadores da área de Administração (stricto sensu) percebem o cenário em que atuam como um espaço de competição e encaram suas relações interpessoais na área como coopetitivas, ou seja, apesar de haver cooperação, destaca-se o clima de competição.

Para a efetiva produção do conhecimento nos programas stricto sensu em Administração, de acordo com Bertero et al. (2013), são necessárias algumas mudanças. Entre elas, os autores destacam o fim da produção científica apenas para a pontuação, sem a preocupação efetiva com o conteúdo e relevância do que é publicado. Algumas práticas, como a obrigação dos discentes do stricto sensu de escreverem e publicarem artigos ao cursarem disciplinas e a inserção de coautores sem contribuição real com a pesquisa realizada desvirtuam a realidade da produção do conhecimento do stricto sensu no país.

Bertero et al. (2013) ainda destacam, em sua pesquisa, o aumento do número de periódicos de Administração no país, responsáveis pelo escoamento da produção acadêmica realizada pelos programas stricto sensu. Alcadipani (2011), por sua vez, ressalta a necessidade de esses periódicos realizarem avaliações mais substantivas, primando pela qualidade, e não pela quantidade do que é publicado. Esse autor afirma que a preocupação excessiva com burocracias, como indexação e fator de impacto, tem tomado mais tempo dos editores do que a qualidade e a relevância do que tem sido publicado em seus periódicos. 


\section{AS INTERAÇÕES ENTRE OS ATORES DA PÓS-GRADUAÇÃO STRICTO SENSU EM ADMINISTRAÇÃO: UMA ANÁLISE DO INDIVÍDUO E DA COLETIVIDADE DOI: http://dx.doi.org/10.5007/1983-4535.2018v11n2p47}

Quanto a sua organização, os programas do stricto sensu da área estão congregados e são representados por meio da Associação Nacional dos Programas de Pós-Graduação em Administração (ANPAD). Esse órgão possui, como finalidade, a promoção do ensino e da pesquisa, bem como a produção de conhecimento nas áreas de Administração, Contabilidade e Turismo (ANPAD, 2014). Além disso, o órgão promove, por meio de eventos científicos na área, a interação entre os programas associados e entre grupos de pesquisa.

Sauerbronn (2013) evidencia que, não obstante a ANPAD realize eventos científícos de porte significativo, há necessidade de ampliar as ações de representação e, ainda, a reconstrução de um espaço para debates substantivos. Segundo Alcadipani (2011), esse órgão precisa ser forte e aberto ao diálogo e à comunidade que representa.

\section{DELINEAMENTO METODOLÓGICO}

Nesta pesquisa busca-se compreender como se relacionam os professores dos programas de stricto sensu em Administração entre si e com os outros atores deste nível de ensino. Portanto, trata-se de uma pesquisa, quanto aos objetivos, de cunho qualitativo, visto que se estudou o fenômeno em profundidade, buscando explicações para sua ocorrência. Investigações dessa natureza consistem em um conjunto de práticas materiais e interpretativas que dão visibilidade ao mundo; assim, seus pesquisadores estudam seus objetos em seus contextos reais, com o objetivo de entender e/ou interpretar os fenômenos em "termos dos significados que as pessoas a ele conferem" (DEZIN; LINCOLN, 2006, p. 17).

No que tange aos procedimentos, classifica-se como um estudo de caso coletivo, pois estudou, conjuntamente, alguns casos para investigar um dado fenômeno, podendo, portanto, ser vista como um estudo instrumental estendido a vários casos. Fez-se a escolha desses casos porque se acredita que seu estudo permite melhor compreensão, ou mesmo melhor teorização, de um conjunto ainda maior de casos (STAKE, 1995).

Para a coleta de dados, contatou-se um professor de cada programa de stricto sensu (mestrado acadêmico e doutorado) de cada programa de Administração. Agendaram-se as entrevistas por região e por estado para agilizar a sua realização e minimizar os custos de deslocamento do pesquisador. Além disso, o pesquisador participou de congressos científicos na área para facilitar a interação com os sujeitos da pesquisa e agendar as entrevistas. Realizou-se parte da coleta nos próprios eventos, conforme a disponibilidade dos sujeitos da 
pesquisa. Em virtude de conflitos de agenda com os sujeitos da pesquisa, realizaram-se, também, entrevistas via web conferência e telefone.

Efetivaram-se vinte e nove entrevistas com os sujeitos da pesquisa entre os meses de maio e outubro de 2013. Gravaram-se as entrevistas na íntegra, com o auxílio de um gravador digital, do que resultou o total de trinta e duas horas e trinta e oito minutos de gravação, com duração média de uma hora e sete minutos cada. Além das entrevistas pesquisou-se também os currículos lattes dos entrevistados, com o intuito de verificar áreas de interesse, publicações e atividades relacionadas a este nível de ensino.

Quanto à análise dos dados, utilizou-se a técnica de análise do conteúdo. Para a categorização, utilizaram-se as técnicas de categorização aberta, axial e seletiva, de Strauss e Corbin (2008).

Ressalta-se que, durante todo o processo de coleta e análise dos dados, se retomou a literatura da área. Da mesma forma, se destaca que, por fundamentar-se na narrativa dos entrevistados, esta pesquisa pode contemplar confusões, enganos e equívocos dos sujeitos que dela participaram (GODOI; BANDEIRA-DE-MELLO; SILVA, 2006), o que se considera uma limitação metodológica. A investigação de múltiplos casos, juntamente com a técnica de triangulação de dados, foi a alternativa utilizada para minimizar as limitações do emprego de um único método.

A técnica de triangulação empregada consiste na coleta de diferentes fontes de dados ou de informações para se chegar ao mesmo resultado (GUION; 2002). Nesta pesquisa, os dados triangulados foram compostos pelas entrevistas, pelos planos de ensino das disciplinas e pelos currículos lattes dos sujeitos da pesquisa. A triangulação, segundo Flick (2009), por manipular diferentes formas de coleta de dados e/ou abordagens teóricas, contribui para a maximização da confiabilidade do processo.

\section{ANÁLISE E INTERPRETAÇÃO DOS RESULTADOS}

$\mathrm{Na}$ análise da interação do professor com outros professores do programa de pósgraduação em que estão inseridos, verificou-se que a interação entre os professores é limitada no aspecto ensino. O Entrevistado 1 ponderou sobre essa interação: “Às vezes você conversa com colegas isolados, não conversa com um grupo [...]. No ensino em si, de graduação e de pós-graduação, tem uma interação muito pequena". 


\section{AS INTERAÇÕES ENTRE OS ATORES DA PÓS-GRADUAÇÃO STRICTO SENSU EM ADMINISTRAÇÃO: UMA ANÁLISE DO INDIVÍDUO E DA COLETIVIDADE DOI: http://dx.doi.org/10.5007/1983-4535.2018v11n2p47}

A pouca interação dos professores no ensino de pós-graduação em Administração contribui para a falta de inovação nas abordagens pedagógicas, pois os professores não dividem seus êxitos e dificuldades nos processos de ensino. Além disso, essa dificuldade de comunicação entre os professores do mesmo programa pode ocasionar sobreposição de conteúdo, visto que professores escolhem o mesmo referencial para suas disciplinas, o que, consequentemente, representa uma falta de alinhamento entre as disciplinas do programa.

No que tange à relação interpessoal dos professores pesquisados com seus colegas de programa de stricto sensu, evidenciaram-se formas distintas de interação. O Entrevistado 4, por exemplo, ressaltou que o clima de trabalho respeitoso consiste em uma "fortaleza" do programa. Segundo esse entrevistado, no programa em que atua, cada professor internaliza seu papel e respeita o do outro. Além disso, as divergências comuns e necessárias para o desenvolvimento do programa não se transformam em "briga" ou desavença pessoal.

Em contraposição, o Entrevistado 5 indicou que mantém um relacionamento problemático com seus colegas de programa em virtude de suas preferências de pesquisa. De acordo com o entrevistado, sua preferência em pesquisar temas de gestão ordinária, do cotidiano, é mal interpretada pelos colegas, além de que a área de Administração em geral, segundo esse entrevistado, ainda possui a mentalidade de ter que pesquisar grandes empresas, tendendo a evitar propostas contrárias a esse padrão.

Assim, evidenciaram-se, nesta pesquisa, diferentes formas de interação entre os professores do programa, tanto positivas quanto negativas. Contudo, tais interações raramente contemplam questões de ensino, conforme ressaltado por todos os entrevistados, com exceção do 2 e do 19.

Em adição, as relações dos professores do programa para pesquisas conjuntas também foram pouco evidenciadas. O Entrevistado 20 apontou que a pouca união entre os professores (pesquisadores) em suas pesquisas consiste em um problema sério dos programas stricto sensu no Brasil. Esse entrevistado também indicou que, embora os programas tenham seus grupos de pesquisa formalizados por questões institucionais, os pesquisadores não atuam em grupo: "É sempre o professor, e seus orientandos em seus projetos de pesquisa, mas na verdade, outros professores não atuam, o grupo não funciona adequadamente".

A pouca interação entre professores de outros programas da mesma instituição também foi ponderada pelo Entrevistado 14, o qual destacou que os procedimentos de interação entre os programas não é claro, principalmente em programas em áreas distintas do 


\section{AS INTERAÇÕES ENTRE OS ATORES DA PÓS-GRADUAÇÃO STRICTO SENSU EM ADMINISTRAÇÃO: UMA ANÁLISE DO INDIVÍDUO E DA COLETIVIDADE DOI: http://dx.doi.org/10.5007/1983-4535.2018v11n2p47}

conhecimento. Evidenciou-se ainda, pela fala do Entrevistado 14, que a interação entre os professores do programa pode se dar por questões formais, como, por exemplo, bancas de qualificação e defesa. Porém, trata-se de relacionamento não sistematizado, com raras possibilidades de publicações conjuntas.

Sobre o intercâmbio entre professores de uma mesma área de diferentes programas, elaborou-se o Quadro 1, no qual constam os principais entraves citados pelos entrevistados.

Quadro 1 Dificuldades de relacionamento entre os professores (pesquisadores)

\begin{tabular}{|c|c|c|}
\hline Sujeito & Trecho em destaque & $\begin{array}{c}\text { Fator } \\
\text { dificultador }\end{array}$ \\
\hline $\begin{array}{c}\text { Entrevistado } \\
4\end{array}$ & $\begin{array}{l}\text { "No Brasil, são contatos esporádicos, porque por incrível que } \\
\text { pareça, os professores no Brasil não sabem responder e-mail. } \\
\text { Você manda e-mail para eles, ninguém te responde. Aqui no } \\
\text { Brasil todo mundo é ocupado demais, todo mundo é importante } \\
\text { demais pra responder. Eu não tenho muita paciência não, então } \\
\text { eu tenho mais contato realmente com o pessoal lá de fora [do } \\
\text { país]". }\end{array}$ & $\begin{array}{l}\text { Problemas de } \\
\text { comunicação }\end{array}$ \\
\hline $\begin{array}{c}\text { Entrevistado } \\
6\end{array}$ & $\begin{array}{l}\text { "O meu principal coautor hoje, que é o professor [..] do } \\
\text { [Universidade], certamente é o principal pesquisador na área de } \\
\text { Administração do Brasil hoje. Mas eu somente o conheci [em } \\
\text { um país da Europa, em um congresso, então, até pra conhecer } \\
\text { um parceiro de pesquisa aqui no Brasil eu precisei estar lá } \\
\text { fora". }\end{array}$ & $\begin{array}{l}\text { Problemas de } \\
\text { comunicação } \\
\text { Falta de } \\
\text { articulação }\end{array}$ \\
\hline $\begin{array}{c}\text { Entrevistado } \\
11\end{array}$ & $\begin{array}{l}\text { "Eu reformulei a disciplina e pedi alguns materiais para outros } \\
\text { professores que trabalham [a disciplina de estratégia], assuntos } \\
\text { pontuais e indicação de artigos ou temáticas. [...] e os } \\
\text { professores em geral são muitos zelosos com seu material [...], } \\
\text { de certa forma os professores se tornam um pouco receosos de } \\
\text { compartilhar isso [o material]". }\end{array}$ & $\begin{array}{l}\text { Concentração do } \\
\text { conhecimento }\end{array}$ \\
\hline $\begin{array}{c}\text { Entrevistado } \\
21\end{array}$ & $\begin{array}{l}\text { "Somos muito independente, temos poucas iniciativas } \\
\text { conjuntas, e eu diria que no [cidade] a gente é mais ainda } \\
\text { independente. Está faltando mais tempo para se integrar, mais } \\
\text { tempo [...]". }\end{array}$ & $\begin{array}{l}\text { Independência } \\
\text { do Pesquisador } \\
\text { Restrição de } \\
\text { tempo }\end{array}$ \\
\hline
\end{tabular}

Fonte: Dados da pesquisa.

Identificaram-se, conforme Quadro 1, fatores, como problemas de comunicação, falta de articulação, restrição de tempo, concentração do conhecimento e independência do pesquisador, que dificultam a interação entre os professores. Salienta-se que tais fatores relacionam-se, fundamentalmente, com as condutas dos professores-pesquisadores.

O Entrevistado 6 indicou, ainda, que, por trabalhar com temas ligados ao Governo, os pesquisadores, no Brasil, não o reconhecem como tal, apesar de publicar e apresentar seus artigos em congressos e periódicos internacionais na área. Essa realidade apresentada reforça a fragmentação do campo e a especialização do conhecimento. Segundo Berger e Luckmann 


\section{AS INTERAÇÕES ENTRE OS ATORES DA PÓS-GRADUAÇÃO STRICTO SENSU EM ADMINISTRAÇÃO: UMA ANÁLISE DO INDIVÍDUO E DA COLETIVIDADE DOI: http://dx.doi.org/10.5007/1983-4535.2018v11n2p47}

(2012), o crescente número de complexidades faz com que subuniversos se tornem inacessíveis aos estranhos, passando a ser hermeticamente vedados aos não iniciados. Dessa forma, o Entrevistado 6, por "não falar a mesma língua" dos demais, acaba excluído desse subuniverso.

Os entrevistados 3, 5 e 14 afirmaram que, normalmente, mantêm relação com professores de outras universidades por meio de bancas. Esse tipo de relacionamento é esporádico e, via de regra, não gera conexões duradouras de pesquisa.

Destaca-se, ainda, que a análise documental, por meio da qual se pesquisou os temas de interesse dos pesquisadores, indicou que há professores com o mesmo tema ou com temáticas complementares de interesse de pesquisa, mas que não se relacionam profissionalmente. O Entrevistado 20 ponderou que uma aproximação desses professores que possuem temáticas próximas ou complementares pode aprimorar a qualidade das pesquisas no Brasil.

As ponderações feitas vão ao encontro dos resultados da pesquisa de Oliveira (2013), o qual concluiu que os pesquisadores da área de Administração (stricto sensu) percebem o cenário em que atuam como um espaço de competição e encaram suas relações interpessoais na área como coopetitivas, ou seja, apesar de haver cooperação, destaca-se o clima de competição.

Analisou-se, também, a interação entre os sujeitos da pesquisa e o contexto profissional (sociedade e mercado) e elaborou-se o Quadro 2, que ressalta as principais falas dos entrevistados sobre o assunto.

As falas apresentadas no Quadro 2 remetem a um distanciamento da área no que se refere às organizações e ao mercado. Ressalta-se a fala do Entrevistado 13, o qual firmou que a universidade não deveria estar em uma "torre de marfim", ou seja, isolada de outros atores do campo. O Entrevistado 24 complementou que essa é uma situação específica da academia brasileira, pois, em outros países, esse distanciamento inexiste.

Contudo, identificaram-se, também, algumas ações dos entrevistados com o intuito de diminuir a distância entre academia (universidade) e mercado (organização). O Entrevistado 25 afirmou que, a partir do resultado de seus estudos científicos, passou a compilar livros, os quais ultrapassaram as barreiras da academia e são lidos por não-acadêmicos. Segundo esse entrevistado, essa prática foi a forma que encontrou para disponibilizar seus estudos e suas pesquisas para a sociedade. 


\section{AS INTERAÇÕES ENTRE OS ATORES DA PÓS-GRADUAÇÃO STRICTO SENSU EM \\ ADMINISTRAÇÃO: UMA ANÁLISE DO INDIVÍDUO E DA COLETIVIDADE \\ DOI: http://dx.doi.org/10.5007/1983-4535.2018v11n2p47}

Quadro 2 Relacionamento entre os sujeitos da pesquisa e a sociedade e o mercado

\begin{tabular}{|c|c|}
\hline eito & Trecho em destaque \\
\hline $\begin{array}{c}\text { Entrevist } \\
13\end{array}$ & $\begin{array}{l}\text { "Eu creio que os programas deveriam ser avaliados mais em termos de relações com a } \\
\text { sociedade. Ou seja, projetos que os programas estão implantando na sociedade, na sua } \\
\text { cidade, na sua região. A influência que os projetos de extensão e de pesquisa estão } \\
\text { exercendo junto às suas comunidades. Porque tem muito projeto que faz um artigo e } \\
\text { pronto. [...] Será que isso está tendo um reflexo na sociedade. A universidade não } \\
\text { deveria estar numa torre de marfim [...] Que resultados trouxe essa pesquisa para o } \\
\text { desenvolvimento da cidade? Ou para as estratégias das empresas? As empresas } \\
\text { passaram a utilizar novas estratégias após a pesquisa?". }\end{array}$ \\
\hline $\begin{array}{c}\text { Entrevis } \\
24\end{array}$ & $\begin{array}{l}\text { "[O campo] cresceu quantitativamente de uma forma absurda, mas para o tamanho do } \\
\text { país ainda é pequena. Mas parece que nós somos ainda só pesquisadores, não atuamos } \\
\text { em uma outra empresa. Nos Estados Unidos e mesmo na Europa ele [o pesquisador] } \\
\text { tem um pé maior nas empresas". }\end{array}$ \\
\hline $\begin{array}{c}\text { Entrevistado } \\
25\end{array}$ & $\begin{array}{l}\text { "O que eu tento fazer é publicar também materiais já digeridos, porque paper } \\
\text { acadêmico ninguém lê, vamos falar a verdade. Então o livro que eu escrevi em } 2010 \\
\text { [Título], eu escrevi para ser de fácil leitura. [...] [O livro] foi essencial para mim porque } \\
\text { muita gente leu. De longe, disparado, foi um dos textos meus que mais gente leu, gente } \\
\text { diferente, não só da academia". }\end{array}$ \\
\hline $\begin{array}{c}\text { Entrevistado } \\
28\end{array}$ & $\begin{array}{l}\text { "Eu procuro aperfeiçoar [a disciplina] a cada momento, e o próximo passo, eu ainda } \\
\text { não sei como vou implementá-la ainda. Mas é preciso trazer mais o dirigente } \\
\text { empresarial para dentro do curso. É fundamental enriquece o debate, mas não é fácil... } \\
\text { o gestor tem agenda cheia". }\end{array}$ \\
\hline $\begin{array}{c}\text { Entrevistado } \\
29\end{array}$ & $\begin{array}{l}\text { "Como é que a gente faz pesquisa se a gente não tem empresa? Fala pra mim... A nossa } \\
\text { área é Administração de Empresas, [...] se eu não for a campo, eu não tenho o que } \\
\text { pesquisar, então eu não posso ter essa distância [...] Eu sempre falo para meus } \\
\text { orientandos, que no trabalho deles tem que haver justificativa prática, essa justificativa } \\
\text { prática é como você vai colaborar com a empresa que está abrindo as portas, ou com a } \\
\text { indústria, com o segmento". }\end{array}$ \\
\hline
\end{tabular}

Fonte: Dados da pesquisa.

O Entrevistado 28 indicou a necessidade de levar o dirigente empresarial para a sala de aula para dividir suas experiências e enriquecer o debate em sala. Apesar de ainda não ter implementado essa ação, em virtude das dificuldades de acesso e disponibilidade dos gestores, o entrevistado considera uma possibilidade de aproximar seu programa e suas aulas do mercado.

A experiência do professor como consultor de empresas, segundo o Entrevistado 29, também representa uma aproximação entre a universidade e as empresas. Esse entrevistado afirmou que os problemas encontrados em seu trabalho como consultor de empresas o motivam a continuar a estudar e a pesquisar na área. Esse mesmo entrevistado complementou mencionando a necessidade de o pesquisador se inserir no ambiente empresarial para realizar suas pesquisas e buscar, além dos resultados teóricos, contribuições práticas para as organizações pesquisadas. 


\section{AS INTERAÇÕES ENTRE OS ATORES DA PÓS-GRADUAÇÃO STRICTO SENSU EM ADMINISTRAÇÃO: UMA ANÁLISE DO INDIVÍDUO E DA COLETIVIDADE DOI: http://dx.doi.org/10.5007/1983-4535.2018v11n2p47}

Os entrevistados 13,24, 25, 28 e 29 identificaram esse distanciamento entre a academia e o mercado como uma fragilidade da área no Brasil. Tais entrevistados realizam ações que, embora isoladas, contribuem para a aproximação dessas áreas. O Entrevistado 13 mencionou que acredita que o modelo de se fazer ciência na área deve mudar nos próximos anos, no sentido de minimizar o distanciamento apresentado.

Os demais entrevistados não comentaram a interação com o contexto profissional (não-acadêmico) em suas atividades. Evidencia-se, então, que, apesar das ações isoladas realizadas por alguns indivíduos (Entrevistados 13, 24, 25, 28 e 29), os acadêmicos da área não adotam condutas para se aproximarem ou para estabelecerem conexões fora do ambiente acadêmico. Os dados ratificam as afirmações de Bailey e Ford (1996) que indicam um distanciamento entre as atividades de ensino nos programas de pós-graduação em Administração americanos e a prática gerencial, os quais se atêm, basicamente, ao que os autores denominaram de cientificismo.

Realizou-se, também, a análise do relacionamento dos entrevistados com os órgãos de financiamento e fomento de pesquisa, entre eles, as fundações de amparo à pesquisa dos estados e o CNPq, conforme organizado no Quadro 3.

Quadro 3 Relacionamento dos sujeitos da pesquisa com órgão de fomento e amparo a pesquisa

\begin{tabular}{|c|c|}
\hline Sujeito & Trecho em destaque \\
\hline $\begin{array}{c}\text { Entrevistado } \\
6\end{array}$ & $\begin{array}{l}\text { "Sou bolsista de produtividade do CNPq, que é uma bolsa [...] que o CNPq } \\
\text { confere para os pesquisadores que ele [CNPq] acha que tem produção } \\
\text { destacada. [...] Fechei um projeto [...] no ano passado [2012] financiado pelo } \\
\text { CNPq, às vezes tem um auxílio para congresso, então sempre tem um auxílio } \\
\text { dos órgãos de fomento". }\end{array}$ \\
\hline $\begin{array}{c}\text { Entrevistado } \\
8\end{array}$ & $\begin{array}{l}\text { "Submeti um projeto ao CNPq para obter uma ajuda para o congresso. Recebi } \\
\text { uma correspondência dizendo que o Comitê a } d \text { hoc tinha considerado relevante } \\
\text { e [...]então pude ir ao [México] apresentar o trabalho no Congresso } \\
\text { Internacional, representando o Banco Mundial. [...] Era um método robusto, } \\
\text { ganhei ainda muito mérito [com o projeto]. Mas se você manda alguma coisa } \\
\text { que já é de lugar comum, vão dar prioridade para outra coisa mais original, é } \\
\text { justo" [grifo nosso]. }\end{array}$ \\
\hline $\begin{array}{c}\text { Entrevistado } \\
15\end{array}$ & $\begin{array}{l}\text { "O CNPq é um meio de fomento. Eu tenho pesquisas financiadas pelo CNPq há } \\
\text { muitos anos, eu praticamente termino um projeto e consigo financiamento para } \\
\text { outro. E tem a bolsa produtividade do CNPq também. Então eu dou muito valor } \\
\text { pra eles }[\mathrm{CNPq}] \text { porque eles realmente estão fazendo um trabalho bacana". }\end{array}$ \\
\hline $\begin{array}{c}\text { Entrevistado } \\
17\end{array}$ & $\begin{array}{l}\text { "São órgãos importantes, no sentido de que são órgãos de fomento. } \\
\text { Principalmente, porque ofertam recursos que você pode eventualmente tentar } \\
\text { obter para financiar suas pesquisas. São órgãos que [...] têm suas falhas } \\
\text { obviamente, mas eu acho que no Brasil eles estão fazendo um bom trabalho[...] } \\
\text { Sempre tem coisas para melhorar, mas dentro do possível, se a gente olhar a } \\
\text { pesquisa no Brasil, a pesquisa no Brasil tem melhorado". }\end{array}$ \\
\hline
\end{tabular}




\section{AS INTERAÇÕES ENTRE OS ATORES DA PÓS-GRADUAÇÃO STRICTO SENSU EM ADMINISTRAÇÃO: UMA ANÁLISE DO INDIVÍDUO E DA COLETIVIDADE DOI: http://dx.doi.org/10.5007/1983-4535.2018v11n2p47}

\begin{tabular}{|c|l|}
\hline Sujeito & \multicolumn{1}{|c|}{ Trecho em destaque } \\
\hline Entrevistado & "Eu já tinha pedido alguns Editais Universais [do CNPq], mas não tinha \\
21 & $\begin{array}{l}\text { levado. Recentemente eu consegui três [apoios], um financiamento de projeto } \\
\text { de pesquisa da FAPERJ, [...] eu ganhei uma Bolsa Produtividade PQ2 [...] e } \\
\text { ganhei também a bolsa de jovens cientistas do nosso estado, da FAPERJ". }\end{array}$ \\
\hline
\end{tabular}

Fonte: Dados da pesquisa.

Os entrevistados 6, 8, 15, 17 e 21, como apontado no Quadro 3, ressaltaram a importância dos órgãos de fomento no apoio aos projetos de pesquisa. Muitas vezes, o apoio do órgão viabiliza a realização de projetos mais ambiciosos, com possibilidade de coleta mais robusta de dados.

Evidencia-se, pelas falas dos entrevistados 15 e 17, que o apoio dos órgãos de fomento aos projetos na área de Administração melhorou nos últimos anos. $\mathrm{O}$ apoio do $\mathrm{CNPq}$, por meio do auxílio à participação em eventos científicos e da bolsa produtividade, também foi enfatizado pelos entrevistados.

Os demais entrevistados não ponderaram a conexão de suas atividades com o apoio de órgãos de fomento. Assim, indica-se que, não obstante possam auxiliar nas ações de alguns sujeitos por meio dos benefícios ressaltados, os órgãos de fomento não geram necessidades de condutas específicas para a representação dos papéis analisados.

Apresenta-se, no Quadro 4, o entendimento dos entrevistados sobre a atuação da CAPES, órgão responsável pela regulação e consolidação dos programas stricto sensu no país.

Quadro 4 Relacionamento dos sujeitos da pesquisa com a CAPES

\begin{tabular}{|c|l|}
\hline Sujeito & \multicolumn{1}{c|}{ Trecho em destaque } \\
\hline Entrevistado & $\begin{array}{c}\text { "Sorte nossa é esse acesso ao portal da CAPES, pois facilita muito. Você tira } \\
\text { um dia, você faz download de uma quantidade enorme de artigos, dá até para } \\
\text { você se afogar de tanta informação". } \\
1\end{array}$ \\
$\begin{array}{c}\text { "O segundo caso são as revistas [científicas], que foram induzidas pela CAPES. } \\
\text { A quantidade de revistas que surgiram é fantástica, a qualidade? Não, qualidade } \\
\text { se faz com o tempo também, vai depender da gente. Em resumo, a função da } \\
\text { CAPES é boa, erra em alguns casos, mas o sistema fica competitivo. Se você } \\
\text { não participa de um programa de pós-graduação, dificilmente você vai } \\
\text { conseguir apoio deles [CAPES] para sua pesquisa". }\end{array}$ \\
$\begin{array}{l}\text { "Teve muita formação de programas [stricto sensu] que buscaram trabalhar } \\
\text { Estratégia, para sair um pouco da Administração. Trouxeram o tema da } \\
\text { estratégia, porque era coqueluche na época de 90, começo de 2000, mas eles } \\
\text { acabaram não entrando para essa área de Estratégia, ficou no nome, no panfleto } \\
\text { apenas. Obviamente que quando aparece um programa que está trabalhando a } \\
\text { Estratégia, o ad hoc da CAPES vai olhar que disciplina de estratégias tem, } \\
\text { quais são os livros de estratégia que o professor está usando [...]. Desta forma, } \\
\text { vejo uma vinculação [da CAPES com os programas]". }\end{array}$ \\
\hline
\end{tabular}




\section{AS INTERAÇÕES ENTRE OS ATORES DA PÓS-GRADUAÇÃO STRICTO SENSU EM ADMINISTRAÇÃO: UMA ANÁLISE DO INDIVÍDUO E DA COLETIVIDADE DOI: http://dx.doi.org/10.5007/1983-4535.2018v11n2p47}

\begin{tabular}{|c|l|}
\hline Sujeito & \multicolumn{1}{c|}{ Trecho em destaque } \\
\hline $\begin{array}{c}\text { Entrevistado } \\
10\end{array}$ & $\begin{array}{l}\text { "Se não fossem eles [CAPES] eu não estaria agora com pós-doutorado [...] Eu } \\
\text { diria que primeiro, pela via do financiamento, que é muito importante, [...] eu } \\
\text { demando pouco recurso, mais para computador e aquisição de livros". }\end{array}$ \\
\hline $\begin{array}{c}\text { Entrevistado } \\
15\end{array}$ & $\begin{array}{l}\text { "A CAPES como tem linha de pesquisa para financiamento de participação em } \\
\text { eventos no exterior, }[. . .] \text { tem alguns colegas de instituições que não tem recurso } \\
\text { [para participação em eventos científicos], que se não fosse a CAPES não } \\
\text { conseguiria participar do evento no exterior". }\end{array}$ \\
\hline
\end{tabular}

Fonte: Dados da pesquisa

Conforme mostra o Quadro 4, o Entrevistado 1 indicou o portal de periódicos da CAPES como uma ferramenta de pesquisa e seleção de artigos da área. Esse entrevistado ainda apontou a "indução" para a criação de revistas científicas na área como uma forma de consolidação do campo. Segundo Pereira, Macadar e Becker (2012), a CAPES, por meio do seu portal eletrônico, especificamente o Portal de Periódicos, legitimou um padrão de acesso ao conteúdo científico e democratizou o conhecimento.

O Entrevistado 5 afirmou que o processo de avaliação da CAPES, por meio do consultor ad hoc que realiza a avaliação nos programas stricto sensu, consiste em um acompanhamento do conteúdo trabalhado em sua disciplina (e demais disciplinas). Segundo o entrevistado, esse processo contribui para a atualização das ementas e referencial bibliográfico das disciplinas e evita que a utilização do seu tema específico ocorra sem estar em consonância com as linhas de pesquisas e propostas dos programas.

As ações de fomento à pesquisa realizadas pela CAPES, por meio da concessão de bolsas de pesquisa e do apoio à participação em eventos científicos internacionais, também foram destacadas pelos entrevistados 10 e 15.

O restante dos entrevistados não destacou um impacto da CAPES diretamente sobre suas condutas. No entanto, os entrevistados 1, 3, 4, 6, 8, 10, 13, 17, 20, 21, 23 e 29 indicaram o sistema de avaliação dos programas de pós-graduação stricto sensu, coordenado pela CAPES, como um fator gerador de necessidades de condutas.

Assim, no que tange à avaliação realizada pela CAPES dos programas stricto sensu em Administração, elaborou-se o Quadro 5, com as falas dos entrevistados sobre esse processo avaliativo.

Em consonância com o Quadro 5, o Entrevistado 1 ponderou que, apesar de determinadas inconsistências, o processo avaliativo implantado pela CAPES tem gerado 


\section{AS INTERAÇÕES ENTRE OS ATORES DA PÓS-GRADUAÇÃO STRICTO SENSU EM ADMINISTRAÇÃO: UMA ANÁLISE DO INDIVÍDUO E DA COLETIVIDADE DOI: http://dx.doi.org/10.5007/1983-4535.2018v11n2p47}

resultados positivos. Porém, o mesmo entrevistado indicou a desistência de pesquisadores em atuar no stricto senso em virtude da pressão decorrente dessa avaliação.

Quadro 5 Entendimento dos sujeitos da pesquisa com o processo de avaliação da CAPES

\begin{tabular}{|c|c|}
\hline Sujeito & Trecho em destaque \\
\hline $\begin{array}{c}\text { Entrevistado } \\
1\end{array}$ & $\begin{array}{l}\text { "Os programas, às vezes, não são tão atrativos [para pesquisadores] em função da } \\
\text { exigência da CAPES. [...] Daqui uns quinze dias eu vou ter esse problema, o triênio } \\
\text { acabou, e meu programa tem o seguinte critério: quem não fizer } 150 \text { pontos, pelo } \\
\text { menos } 150 \text { pontos, vai ser descredenciado. Isso gera um problema político infernal". } \\
\text { "Cada triênio o sarrafo aumenta, cada triênio é isso. Que é desafiador, algumas pessoa } \\
\text { já não concordam, há um certo exagero aqui e acolá, alguns inconsistentes, mas eu acho } \\
\text { que o resultado final é muito bom". }\end{array}$ \\
\hline $\begin{array}{c}\text { Entrevistado } \\
3\end{array}$ & $\begin{array}{l}\text { "Ela [CAPES] como indutora disso [avaliação], eu acho importante, obviamente que } \\
\text { eu, como professor de um programa stricto sensu, eu sempre digo para os meus pares, } \\
\text { querem criticar a CAPES? Tira sete [Nota Máxima]. No dia que tirar sete, você tem } \\
\text { lastro para detonar a CAPES. Agora, tira três e quer dizer que a regra está errada?". }\end{array}$ \\
\hline $\begin{array}{c}\text { Entrevistado } \\
4\end{array}$ & $\begin{array}{l}\text { "Há uma pressão produtivista. Você acaba fazendo determinadas concessões, por } \\
\text { exemplo, um artigo que você sabe que não tem a menor chance de emplacar em um } \\
\text { [periódico] B2, você manda para um B3 ou B4 para garantir ponto. Por essa pressão de } \\
\text { pontos, eu acabo escrevendo artigos para fazer os pontos. Agora a hora que eu vejo que } \\
\text { os pontos já estão garantidos naquele triênio, então eu vou trabalhar o que realmente eu } \\
\text { gosto, que são esses artigos que eu pretendo mandar para journals internacionais. Antes } \\
\text { de garantir os pontos não, você fica naquele produtivismo mesmo. O que eu acho } \\
\text { péssimo". }\end{array}$ \\
\hline $\begin{array}{c}\text { Entrevistado } \\
6\end{array}$ & $\begin{array}{l}\text { "Eu sou um crítico em relação a esse quadro [avaliação CAPES]. Eu acho que ele } \\
\text { acaba premiando o produtivismo, ele é uma ordem ao produtivismo, então se produz } \\
\text { qualquer coisa, não necessariamente boa". }\end{array}$ \\
\hline $\begin{array}{c}\text { Entrevistado } \\
8\end{array}$ & $\begin{array}{l}\text { "É uma das coisas que me incomoda [avaliação CAPES], porque muitas vezes você } \\
\text { pode produzir muito ajudando alunos, atuando como um consultor em sala de aula, ser } \\
\text { convidado para fazer palestra na empresa, e nada disso conta um ponto. [...] Me } \\
\text { desagrada profundamente esses critérios da pontuação e da pressão da pontuação. Hoje } \\
\text { se publica qualquer coisa só para publicar, e esse não é meu estilo". }\end{array}$ \\
\hline $\begin{array}{c}\text { Entrevistado } \\
17\end{array}$ & $\begin{array}{l}\text { "Tenho algumas restrições [ao sistema de avaliação da CAPES]. Acho que é mais } \\
\text { importante você fazer um bom trabalho de qualidade a cada três anos do que fazer dez } \\
\text { trabalhos de baixa qualidade no mesmo período. Acho que a CAPES peca um pouco } \\
\text { porque ela tá exigindo quantidade e não qualidade". }\end{array}$ \\
\hline $\begin{array}{c}\text { Entrevistado } \\
20\end{array}$ & $\begin{array}{l}\text { "A forma sistemática da CAPES de cobrança, de avaliação, dos programas de pontos } \\
\text { não me afeta muito. Eu não me afeto diretamente porque não estou preocupado em } \\
\text { pontuar simplesmente. Eu estou preocupado em produzir e orientar e ajudar os alunos a } \\
\text { desenvolver pesquisa". }\end{array}$ \\
\hline $\begin{array}{c}\text { Entrevistado } \\
21\end{array}$ & $\begin{array}{l}\text { "Mais do que buscar simplesmente pontos, eu estou buscando menos journals, e mais } \\
\text { journals bons. [Estou] fazendo um esforço maior, para escrever artigos melhores para } \\
\text { journals melhores e uma quantidade menor de artigos". }\end{array}$ \\
\hline $\begin{array}{c}\text { Entrevistado } \\
23\end{array}$ & $\begin{array}{l}\text { "A gente não tá produzindo para disseminar conhecimento. A gente está produzindo } \\
\text { para pontuar, mas porque existe um sistema que cobra do Prof. a pontuação. [...] } \\
\text { ninguém tá preocupado com a qualidade do seu artigo, ou com o tipo de conhecimento } \\
\text { que ele tá gerando. Quando a Capes vai avaliar, ela vai avaliar quantos pontos você fez. } \\
\text { [...] E é isso que vai gerar a bolsa produtividade, que garante financiamento para suas } \\
\text { pesquisas. [...] Não tem como não pensar [em pontos] quando você está dentro de um } \\
\text { sistema que te pressiona } 24 \text { h para pontuação, e que não considera os outros trabalhos } \\
\text { que você tem na área acadêmica, como pontuação". }\end{array}$ \\
\hline
\end{tabular}

Fonte: Dados da pesquisa. 


\section{AS INTERAÇÕES ENTRE OS ATORES DA PÓS-GRADUAÇÃO STRICTO SENSU EM \\ ADMINISTRAÇÃO: UMA ANÁLISE DO INDIVÍDUO E DA COLETIVIDADE \\ DOI: http://dx.doi.org/10.5007/1983-4535.2018v11n2p47}

Os demais entrevistados $(3,4,6,8,17)$ criticaram o sistema de avaliação da CAPES dos programas stricto sensu implantado, principalmente no que tange à pressão realizada pelo sistema de pontos. O Entrevistado 23 indicou que esse sistema não mensura a criação e a disseminação do conhecimento e que estabelece a prática de publicação frenética de artigos, sem o necessário cuidado quanto à qualidade e relevância do que é pesquisado.

O entrevistado 4 afirmou que gostaria de realizar pesquisas mais profundas, com maior tempo para a coleta de dados e para a reflexão do pesquisador sobre os resultados da pesquisa. Esses entrevistados, entretanto, acabam abrindo concessões no que tange à qualidade de suas pesquisas para poder atingir a pontuação indicada pelo órgão regulador.

O Entrevistado 21 demonstrou, por meio de sua fala, uma postura contrária ao padrão até então estabelecido e afirmou dar mais atenção para a qualidade de suas publicações do que para a quantidade de artigos gerados. O Entrevistado 20 também demonstrou um interesse em produzir conhecimento e em amparar os alunos em suas pesquisas, em detrimento da publicação em busca de pontos.

O Entrevistado 23 ressaltou que o sistema por pontos implantado pela CAPES regula a concessão de bolsas de produtividade e o apoio financeiro aos projetos de pesquisa. Dessa forma, os indivíduos se sentem forçados a adotar o sistema, pois, caso contrário, serão excluídos de seus respectivos programas.

Os resultados, nesse sentido, convergem para as conclusões de Santos (2004), que indicam que as limitações do sistema de avaliação por pontos influenciam os programas no sentido de não valorizar o que não pode ser mensurado, e que, dessa forma, o planejamento e a promoção de atividades fora dos indicadores do sistema são preteridos.

Perguntou-se, ainda, aos entrevistados, se o sistema de avaliação da CAPES e a atuação desse órgão exercem pressão sobre o conteúdo de suas pesquisas. Confeccionou-se o Quadro 6 a partir das respostas obtidas.

Como abordado no Quadro 6, os entrevistados 3, 5, 11 e 16 indicaram a independência do pesquisador na escolha dos seus temas de interesse. Percebe-se que a influência da CAPES se dá, portanto, no ritmo e na quantidade de publicações, mas não interfere diretamente no tema de pesquisa.

Contudo, os entrevistados 10, 23 e 29 relacionaram o estabelecimento de condutas para a publicação, decorrente do sistema de avaliação em análise, com as escolhas metodológicas para pesquisa. Segundo esses entrevistados, as pesquisas realizadas por meio 


\section{AS INTERAÇÕES ENTRE OS ATORES DA PÓS-GRADUAÇÃO STRICTO SENSU EM \\ ADMINISTRAÇÃO: UMA ANÁLISE DO INDIVÍDUO E DA COLETIVIDADE \\ DOI: http://dx.doi.org/10.5007/1983-4535.2018v11n2p47}

da abordagem quantitativa possuem maior facilidade de publicação de artigos, especialmente no Brasil, e indicaram uma preferência da área por pesquisas quantitativas.

Quadro 6 Entendimento dos sujeitos da pesquisa quanto à influência da CAPES sobre suas Pesquisas

\begin{tabular}{|c|l|}
\hline Sujeito & \multicolumn{1}{c|}{ Trecho em destaque } \\
\hline $\begin{array}{c}\text { Entrevistado } \\
3\end{array}$ & $\begin{array}{l}\text { "Eu tenho algum interesse, e por esse interesse surge um projeto de pesquisa, que é ou } \\
\text { não aprovado pela CAPES. Mas o fato de não ser aprovado, vai ser elaborado do } \\
\text { mesmo jeito, independe da CAPES, porque se for [financiado] pela CAPES, melhor, } \\
\text { porque vai ter dinheiro, se não for pela CAPES, vai ser de alguma maneira, vai se } \\
\text { arranjar esse dinheiro de outra forma. Portanto, a influência [da CAPES] em relação ao } \\
\text { tema a ser desenvolvido é nenhuma". }\end{array}$ \\
\hline $\begin{array}{c}\text { Entrevistado } \\
5\end{array}$ & $\begin{array}{l}\text { "A CAPES, propriamente dita, não vai funcionar como uma grande influenciadora. Ela } \\
\text { não tem esse papel, ainda bem. Ela vai influenciar programas, é outra coisa". }\end{array}$ \\
\hline $\begin{array}{c}\text { Entrevistado } \\
11\end{array}$ & $\begin{array}{l}\text { "Eu nunca me candidatei a nenhum edital de pesquisa dessa natureza, sempre os editais } \\
\text { foram abertas do ponto de vista de escopo, então não recebo nenhuma influência como } \\
\text { pesquisador de nenhuma agência de fomento. Não existe isso". }\end{array}$ \\
\hline $\begin{array}{c}\text { Entrevistado } \\
16\end{array}$ & $\begin{array}{l}\text { "Eu diria que eu não tenho nenhuma influência deles [órgãos de fomento]. Eu escolhi } \\
\text { as coisas porque me interessei. E os projetos que eu tive foram aprovados. Então fiz o } \\
\text { projeto em função do interesse. Não foi por que saiu no edital, que era importante } \\
\text { pesquisar isso ou aquilo". }\end{array}$ \\
\hline
\end{tabular}

Fonte: Dados da pesquisa.

Dessa forma, como decorrência da pressão por pontuação realizada pela CAPES e a possível facilidade de publicação de pesquisas realizadas com abordagem quantitativa indicada pelos entrevistados, pode-se verificar um fator que contribui para o direcionamento dos padrões de ação dos pesquisadores para esse tipo de abordagem metodológica.

O estabelecimento de padrões de ação com o objetivo de aumentar as publicações também é evidenciado por Oliveira (2013), que identificou relações de colaboração entre pesquisadores para maximizar seu ganho em pontos. Alcadipani (2011) indica a necessidade de o pesquisador resistir ao produtivismo e de adotar condutas que valorizem a formação dos alunos e a produção acadêmica de qualidade. Apesar de identificar a necessidade de reformulação do sistema de avaliação da CAPES por pontos, o autor ressalta que o órgão apenas estabelece a necessidade de pontos mínimos. As condutas do produtivismo são estimuladas em função das pressões dos programas para obterem boa avaliação e da competitividade entre os pesquisadores para terem mais pontos.

Outro elemento analisado nesta pesquisa foi a função dos congressos científicos para o aprimoramento do campo científico. No que se refere a importância dos congressos científicos para a interação dos atores do campo, os entrevistados 2, 6, 19 e 20, indicaram que os 


\section{AS INTERAÇÕES ENTRE OS ATORES DA PÓS-GRADUAÇÃO STRICTO SENSU EM \\ ADMINISTRAÇÃO: UMA ANÁLISE DO INDIVÍDUO E DA COLETIVIDADE \\ DOI: http://dx.doi.org/10.5007/1983-4535.2018v11n2p47}

congressos científicos servem para potencializar o trabalho em rede, no qual pesquisadores de universidades diferentes realizam pesquisas em conjunto.

Os entrevistados 2, 6 indicaram, ainda, que as experiências trocadas durante os encontros alimentam o pesquisador com novas ideias e perspectivas para avançar em suas pesquisas. O Entrevistado 11 apresentou a possibilidade de ter avaliações rápidas de seu trabalho por meio da submissão de suas pesquisas em eventos. Segundo esse entrevistado, mesmo que, nos eventos, os resultados sejam parciais, servem para indicar ao pesquisador os pontos fortes e fracos de seu trabalho. Assim, a avaliação realizada pelos pares (blind review) em congressos gera argumentos para o pesquisador refletir sobre sua pesquisa e melhorá-la antes de submetê-la a um periódico.

A realização de painéis com conferencistas de renome nacional e internacional foi apontada pelo Entrevistado 20 como um espaço positivo para o debate e para a troca de experiências e a consequente promoção do desenvolvimento da área.

Os entrevistados também indicaram desvantagens dos congressos científicos. Os entrevistados 3 e 4, por exemplo, apontaram que a mudança de critérios realizada no sistema de avaliação da CAPES, em 2008, segundo a qual o evento científico deixou de gerar pontos para a índice de publicação do pesquisador, desmotiva-os a participar de eventos científicos.

Além disso, os entrevistados 4, 8, 11 e 13 indicaram o elevado preço dos congressos científicos e a diminuição do auxílio financeiro das universidades para a participação em eventos como fator limitador para frequentar congressos científicos.

A falta de debate e interação nas sessões dos congressos científicos também foi apontada pelos entrevistados 7 e 15 como uma desvantagem dos congressos científicos realizados no Brasil. O Entrevistado 9 complementou a crítica indicando que os eventos deixaram de ter cunho científico e passaram a ter cunho político.

Os entrevistados 4, 13 afirmaram que, devido às deficiências apontadas (alto custo, pouco debate e não-consideração no sistema de pontuação), os congressos científicos passaram a ser encontros de alunos que participam esporadicamente para apresentar seus trabalhos, via de regra, em virtude de critérios dos programas para a conclusão do curso.

No que tange à atuação da ANPAD como ator que representa os interesses dos cursos stricto sensu em Administração, o Entrevistado 7 apontou um direcionador do campo, com a indicação de áreas e temas em evidência. Contudo, esse entrevistado afirmou que se trata "mais de uma influência passiva". Quanto à atuação da ANPAD no campo científico, o 


\section{AS INTERAÇÕES ENTRE OS ATORES DA PÓS-GRADUAÇÃO STRICTO SENSU EM ADMINISTRAÇÃO: UMA ANÁLISE DO INDIVÍDUO E DA COLETIVIDADE DOI: http://dx.doi.org/10.5007/1983-4535.2018v11n2p47}

Entrevistado 19 pontuou que a ANPAD legitima o produtivismo resultante do sistema de pontuação da CAPES.

Nesse sentido, os dados da pesquisa convergem para as afirmações de Alcadipani (2011), que indica a necessidade de a ANPAD rever sua atuação, fundamentalmente na representação dos interesses do grupo frente às entidades reguladoras.

O Entrevistado 15 realçou o desenvolvimento da plataforma Scientific Periodicals Electronic Library (SPELL) como indexador de artigos nacionais como a maior ação da ANPAD nos últimos anos. Contudo, o entrevistado, juntamente com os entrevistados 7, 9 e 13, apontou que o órgão atua mais como um organizador de eventos, em detrimento do seu objetivo principal de fomentar pesquisas. Em algumas entrevistas, quando se perguntou sobre a atuação da ANPAD, os entrevistados responderam que ocorre por meio da análise da importância da realização e da participação em eventos científicos, o que reforça as afirmações dos entrevistados 7, 9, 13 e 15.

Esses resultados contemplam as críticas de Sauerbronn (2013) à ANPAD, as quais indicam ações inexpressivas do órgão de representação e solicitam a reconstrução de um espaço para debates substantivos.

Nesta subseção, na qual se discorreu sobre as relações com outros atores do campo, buscou-se identificar e analisar a ação de outros atores do campo que impactam na atuação do papel de professor e pesquisador. Conforme apresentado, a relação com outros professores da universidade em que atua, o contato com outros professores de outras universidades, o impacto dos órgãos de fomento à pesquisa, do órgão regulador (CAPES) e da associação dos programas em Administração (ANPAD) evidenciam que o papel social do professor/pesquisador não pode ser analisado individualmente.

A análise do papel dos outros atores realizada nesta subseção corrobora o postulado de Berger e Luckmann (2012), o qual indica que a análise sobre como o indivíduo se relaciona com a coletividade contempla, necessariamente, um exercício de análise de papéis.

\section{CONSIDERAÇÕES FINAIS}

Nesta pesquisa objetivou-se compreender a interação dos professores dos programas de stricto sensu em Administração entre si e com os outros atores deste nível de ensino. Analisaram-se, neste sentido, a relação dos sujeitos da pesquisa com os outros atores do campo em estudo, entre eles: outros professores da universidade em que atuam, os professores 


\section{AS INTERAÇÕES ENTRE OS ATORES DA PÓS-GRADUAÇÃO STRICTO SENSU EM ADMINISTRAÇÃO: UMA ANÁLISE DO INDIVÍDUO E DA COLETIVIDADE DOI: http://dx.doi.org/10.5007/1983-4535.2018v11n2p47}

de outras universidades, os órgãos de fomento à pesquisa, o órgão regulador dos programas stricto sensu (CAPES) e a associação dos programas de pós-graduação em Administração (ANPAD).

Ressalta-se que a análise do campo apresentada não é exaustiva, em virtude da possibilidade de haver outros atores influenciando a atuação do professor (pesquisador). Salienta-se, ainda, que as relações ora analisadas estão restritas ao papel de professorpesquisador. Dessa forma, outros papéis que o indivíduo desempenhe (orientador, avaliador, editor, etc.) não foram contemplados em virtude de limitações da pesquisa.

Verificou-se que os problemas de comunicação, a falta de articulação, a restrição de tempo, a concentração do conhecimento e a independência do pesquisador dificultam a interação entre os professores. Evidenciou-se, ainda, que as atividades de interação existentes entre os professores raramente contemplam questões de ensino.

Identificou-se, ainda, os órgãos como o CNPq, as Fundações Estaduais de Fomento e a CAPES como entidades que participam do campo em análise. Inferiu-se que as condutas desses outros atores não impactam a seleção do tema de pesquisa do pesquisador, podendo, contudo, influenciar as formas de ação dos pesquisadores por meio do auxílio à participação em eventos científicos, financiamento de projetos e bolsas de pesquisa.

Esse tipo de análise considera os postulados de Berger e Luckmann (2012), os quais indicam que a análise da maneira como o indivíduo se relaciona com a coletividade será necessariamente um exercício de análise de papéis.

Nesse sentido, destacam-se os padrões de conduta estimulados pelo sistema de avaliação da CAPES, por meio do estabelecimento da métrica de pontos para a publicação. Esse sistema de avaliação suscita uma (super)valorização da produtividade e contribui para a conduta das publicações sucessivas, sem a necessária preocupação com a qualidade do material gerado. A preocupação preferencial pela quantidade de pontos gerados por triênio também reflete as indicações de Santos (2004), o qual afirma que as condutas dos professores passam a preterir atividades que estão fora dos indicadores do sistema de avaliação da CAPES.

Verificaram-se, ainda, a contribuição dos eventos científicos como momentos de integração entre os pesquisadores da área. Contudo, a não-pontuação, pela CAPES, das publicações em eventos, o elevado custo dos eventos e a pouca contribuição nas sessões de 
apresentação de trabalhos foram ressaltados como fatores inibidores da participação dos entrevistados nos congressos científicos.

No que tange à atuação da ANPAD, notou-se sua contribuição na criação de um portal indexador dos trabalhos científicos nacionais na área, além da organização dos principais eventos que congregam esse campo de estudos (ENANPAD e 3Es). Entretanto, os entrevistados indicaram a deficiência do órgão em desempenhar seu objetivo principal de fomentar pesquisas. Essa necessidade de readequação das atividades da ANPAD também é ressaltada por Alcadipani (2011).

Quanto às limitações da pesquisa, a representação do papel social ficou restrita à interpretação que os sujeitos da pesquisa fizeram de seu próprio papel, podendo conter enganos, estimativas e supervalorizações dessas interpretações. Reforça-se, contudo, que a análise de múltiplos casos, a triangulação na coleta de informações, as categorizações sucessivas e estruturadas e a comparação dos resultados com a teoria na área foram empregadas neste trabalho com o intuito de minimizar tais ocorrências.

\section{REFERÊNCIAS}

ALCADIPANI, Rafael. Resistir ao produtivismo: uma ode à perturbação acadêmica. Cadernos EBAPE. BR, v. 9, n. 4, p. 1174-1178, 2011.

BAILEY, James; FORD, Cameron. Management as science versus management as practice in postgraduate business education. Business Strategy Review, v. 7, n. 4, p. 7-12, 1996.

BERGER, Peter L.; LUCKMANN, Thomas. A Construção Social da Realidade: tratado de sociologia do conhecimento. Rio de Janeiro: Vozes, 2012.

BERTERO, C. Ensino e Pesquisa em Administração, Thompson Learning, São Paulo, 2006.

BERTERO, Carlos O.; ALCADIPANI, Rafael; CABRAL, Sandro; FARIA, Alexandre;

ROSSONI, Luciano. Os desafios da produção de conhecimento em Administração no Brasill. Cadernos EBAPE. BR, v. 11, n. 1, p. 181-196, 2013.

CAPES. Coordenação de Aperfeiçoamento de Pessoal de Nível Superior. Cursos recomendados e reconhecidos, 2013. Disponível em: $<$ http://www.capes.gov.br $>$. Acesso em: 23 maio 2014.

DANTAS, F. Responsabilidade social e pós-graduação no Brasil: idéias para (avali)ação. RBPG - Revista Brasileira de Pós-graduação, v. 1, n. 2, p. 141-159, nov., 2004. 
DENZIN, Norman K.; LINCOLN, Yvonna S. O planejamento da pesquisa qualitativa: teorias e abordagens. Porto Alegre: Artmed, 2006.

FLICK, Uwe. Introdução a pesquisa qualitativa. 3. Ed. Porto Alegre: Artmed, 2009. GODOI, C. K.; BANDEIRA-DE-MELLO, R.; SILVA, A. B. (org.). Pesquisa qualitativa em estudos organizacionais: paradigmas, estratégias e métodos. São Paulo: Saraiva, 2006. p. 115-146.

GUION, Lisa A. Triangulation: establishing the validity of qualitative studies. Gainesville: University of Florida, 2002.

IKEDA, Ana A.; CAMPOMAR, Marcos C.; VELUDO-DE-OLIVEIRA, Tânia M. A Pósgraduação em Administração no Brasil: definições e esclarecimentos. Gestão \& Planejamento-G\&P, v. 1, n. 12, 2008.

MACCARI, Emerson. Contribuições à gestão dos programas de pós-graduação stricto sensu em administração no Brasil com base nos sistemas de avaliação norte americano e brasileiro. 250 p., Tese (Doutorado em Administração) - Programa de Pós-Graduação em Administração, Universidade de São Paulo, São Paulo, 2008.

MELlO, Cristiane M. de; CRUBELlATE, João M.; ROSSONI, Luciano. Redes de coautorias entre docentes de programas brasileiros de pós-graduação (stricto sensu) em administração: aspectos estruturais e dinâmica de relacionamento. Revista de Administração Mackenzie, v. 10, n. 5, p. 130-153, set./out., 2009.

OLIVEIRA, Caio C. Giannini. Coopetição em redes interpessoais: relacionamentos coopetitivos na rede de pesquisadores brasileiros em Administração. 2013. 132p. Tese (Doutorado em Administração) - Programa de Pós-Graduação em Administração, Pontifícia Universidade Católica de Minas Gerais, Belo Horizonte, 2013.

PEZI, Silvana; STEIL, Andrea V. Análise do processo de exame de grau na pós-graduação stricto sensu. Educação e Pesquisa, v. 35, n. 1, p. 033-050, jan./abr., 2009.

PEREIRA, Gabriela V.; MACADAR, Marie A.; Becker, Grace V. Análise do uso do Portal de Periódicos da CAPES em uma IES sob Perspectiva Institucional. In: ENANPAD, 36., 2012, Rio de Janeiro. Anais... Rio de Janeiro: ANPAD, 2012.

SANTOS, L. L. C. Formação de professores na cultura do desempenho. Educação \& Sociedade, v. 25, n. 89, p. 1145-1158, 2004.

SAUERBRONN, João F. R. Diga-me o que publicas e te direi quem és: Perspectivas e resistências na publicação da produção de conhecimento em Marketing. Revista de Negócios, v. 18, n.1, p. 42-52, jan./mar., 2013.

STAKE, Robert E. The art of case study research. London: Sage Publications, 1995. STRAUSS, Anselm; CORBIN, Juliet. Pesquisa qualitativa: técnicas e procedimentos para desenvolvimento de teoria fundamentada. 2. Ed. Porto Alegre: Artmed, 2008. 